\title{
RESEARCH
}

Open Access

\section{How does membership in local savings groups influence the determinants of national health insurance demand? A cross-sectional study in Kisumu, Kenya}

Tessa Oraro ${ }^{1,2,3^{*}}$ (D) and Kaspar Wyss ${ }^{1,2}$

\begin{abstract}
Background: Rotating savings and credit associations (ROSCAs) are highly active in many sub-Saharan African countries, serving as an important gateway for coping with financial risk. In light of the Kenya's National Hospital Insurance Fund's (NHIF's) strategy of targeting ROSCAs for membership enrolment, this study sought to estimate how ROSCA membership influences the determinants of voluntary health insurance enrolment.

Methods: A cross-sectional survey of 444 households was carried out in Kisumu City between July and August 2016. A structured questionnaire was administered on health insurance membership, household attributes, headship characteristics and health-seeking behaviour. We assessed the influence of ROSCA membership on the associations between NHIF enrolment and the explanatory variables using univariate logistic regression.

Results: The study found that education was associated with NHIF demand regardless of ROSCA membership. Both ROSCA and non-ROSCA households with high socioeconomic status showed stronger health insurance demand compared with poorer households; there was, however, no evidence that the strength of this association was influenced by ROSCA status ( $p$-value $=0.47$ ). Participants who were self-employed were significantly less likely to enrol into the NHIF if they did not belong to a ROSCA (interaction test $p$-value $=0.03$ ). NHIF enrolment was found to be lower among female-headed households. There was a borderline effect of ROSCA membership on this association, with a lower odds ratio amongst non-ROSCA members ( $p$-value $=0.09$ ): the low treatment numbers amongst the insured infers that ROSCA membership may play a role on the association between gender and NHIF demand.

Conclusions: Our findings suggest that ROSCA membership may play a role in increasing health insurance demand amongst some traditionally under-represented groups such as women and the self-employed. However, the strategy of targeting ROSCAs to increase national health insurance enrolment may yield exiguous results, given that ROSCA membership is itself influenced by several non-observable factors - such as time-availability and selfselection. It is therefore important to anchor outreach to ROSCAs within a broader, multi-pronged approach that targets households within their social, economic and political realities.
\end{abstract}

Keywords: ROSCAs, Health insurance, Social capital, Kenya

\footnotetext{
* Correspondence: tessa.oraro@swisstph.ch

${ }^{1}$ Swiss Tropical and Public Health Institute, Basel, Switzerland

2University of Basel, Basel, Switzerland

Full list of author information is available at the end of the article
}

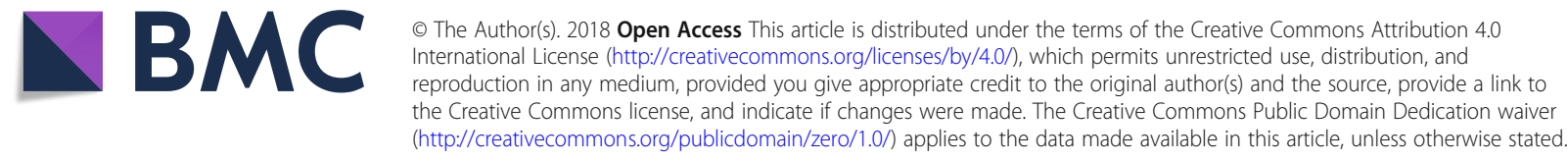




\section{Introduction}

Informal economic networks based on geographical, sociocultural or occupational proximity are highly active in many sub-Saharan African countries, with an estimated $24 \%$ of the population participating in local savings clubs in 2014 [9]. In Kenya, where $24.6 \%$ of the population is excluded from formal savings and loans institutions, local rotating savings and credit associations (ROSCAs) have emerged as important gateways for coping with financial instability [7]. ROSCAs are typically created to meet an unmet social and economic need amongst vulnerable groups such as the working poor and women $[2,9]$, with participants pooling their financial resources to create communal savings funds as a form of financial risk protection [42]. In this sense, ROSCAs serve as social networks through which individuals obtain financial security through collective resource mobilisation. Due to their informal nature, ROSCAs' success is contingent upon the trust, reciprocity and collective strength shared amongst group members - fundamental components of a phenomenon known as social capital [12, 42]. It is this reliance on social capital that has driven the use of similar welfare associations as launchpads for the national health insurance schemes in Germany and Japan $[6,36]$.

Against the backdrop of increasing ROSCA membership across sub-Saharan Africa, financial risk protection in health care has remained low. Several governments in the region such as those in Ghana and Kenya have sought to promote national health insurance schemes as a means of minimising the high out-of-pocket costs associated with ill health [38, 39]. In Kenya - where up to $28 \%$ of slum-dwelling households face catastrophic health expenditure [5] - the national government has established the National Hospital Insurance Fund (NHIF) as a means of providing financial risk protection to its citizens. The NHIF operates like most national health insurance schemes in the region, with the government and the formal sector providing the bulk of financial contributions to the scheme [40]. However, given the high levels of informal employment in the Kenyan economy, the depth of insurance coverage has remained low, with only $13.5 \%$ of the population receiving NHIF coverage [20]. A large proportion of Kenya's informally employed households - who constitute $85 \%$ of the working population - are thus left susceptible to financial shocks in the event of ill health $[20,41]$. This problem echoes findings across health insurance schemes in several sub-Saharan countries, where low health insurance demand has been attributed to high levels of labour informality.

As part of efforts to better understand the reasons behind the low uptake of voluntary health insurance, several research studies have identified a link between social solidarity and health insurance demand across various sub-Saharan African settings [1, 14]. This growing body of evidence has led Kenyan policymakers to target ROSCAs as a means of increasing NHIF demand amongst the informal sector, in line with their role as vehicles for social solidarity [33]. Consequently, we seek to understand how ROSCA membership influences the drivers of voluntary health insurance in Kisumu, Kenya. This paper will be structured as follows: We will first provide a review of the research on the intersection between local group membership, social capital, and voluntary health insurance membership. We will subsequently report our methodology and results, and conclude with an analysis of our findings.

In order to better understand the mechanisms through which ROSCAs may influence health insurance enrolment, it is first necessary to define the social capital underpinning the success of ROSCAs. Social capital as a concept focuses on the utility of relationships and resources in facilitating collaboration towards a common goal $[4,8,34]$. While different interpretations of its nature and effect exist, it is generally agreed that social capital influences the depth of individuals' engagement with local and national structures by facilitating trust and reciprocity within communities. ROSCAs - as local informal groupings - seek to empower economic cooperation in the face of complex resource and capacity constraints. In doing so, they tap into two key dimensions of social capital: intraand inter-community collaborations. When constituting ROSCAs in low-resource settings, members often recruit those in whom they have inherent trust - ostensibly those with similar socioeconomic, professional or ethno-cultural characteristics. This structure mimics traditional African obligations to familial and tribal alliances [3], and derives its power from harnessing existing links within homogenous groups: a concept known as bonding social capital [30]. Concurrently, in order to make ROSCAs sustainable, members seek to increase the associations' capital base and minimise the risk of default [2]. They thus expand their radius of trust beyond their typical personal, sociocultural and organisational bases - a phenomenon known as bridging social capital [30]. In this vein, ROSCAs foment economic, social, and cultural links within local communities [35].

In spite of the pervasiveness of ROSCAs and their linkages to national health insurance enrolment in several sub-Saharan African settings [24, 27], there remains a paucity of research on the influence of ROSCAs on national health insurance demand. We can, however, draw lessons from studies carried out on the influence of social capital as a general concept on voluntary health insurance enrolment. According to existing research, active members of local mutual assistance groups such as ROSCAs are more likely to be part of voluntary health insurance schemes 
due to a shared ethos of social cooperation [11, 15, 31]. These findings highlight the importance of common norms, values and objectives - characteristic features of social capital - in influencing households' decision to enrol into voluntary health insurance. Given this, our paper will seek to answer the following research question: How does ROSCA membership influence the determinants of voluntary health insurance enrolment? We will further seek to understand how existing knowledge on social capital can help explain the influence of ROSCAs on the determinants of health insurance demand.

In order to answer these questions, we can apply several hypotheses to our study based on the findings of existing research. Given the link identified between local informal group membership and social capital, we anticipate that non-ROSCA members may have weaker bonding and bridging social capital compared with their ROSCA member counterparts. As a result of this, we expect wealth to manifest as an overarching determinant of NHIF demand amongst non-ROSCA members in line with existing national health financing studies [10, 17, 18, 24, 26, 27]. Additionally, we hypothesise that sociocultural sensitivities such as household composition; gender of household head; and marital status will influence households' likelihood of enrolling into national health insurance [10, 17, 18, 24-27]. We however postulate that these inequities may be reduced by ROSCA membership due to their high social capital stock.

\section{Methodology}

\section{Sampling methodology}

A cross-sectional household survey was carried out in Kisumu City between July and August 2016 to identify the extent to which NHIF enrolment is influenced by ROSCA membership; household composition and attributes; as well as household head characteristics such as occupation, age, gender and perceived health status of household members.

Our study aimed to estimate the proportion of the informally employed population with voluntary NHIF health insurance, and to assess the association between explanatory variables and this proportion. In order to achieve these aims, we calculated the sample size based on the ability to estimate the proportion insured with a certain precision - in this case, with an expected NHIF population coverage of $13.8 \%$ [29]. Using the Hayes and Bennett equation and taking into account clustering in six sub-locations across Kisumu, required sample size was calculated to be 440 households with the precision of a $95 \%$ confidence interval with a width of 10 to $18 \%$ [16]. The number of households interviewed in each sub-location was proportional to its demographic size, which was obtained from the 2009 Kenya Population and Housing Census [22].
Multistage cluster sampling was used to obtain the study sample, with enumeration maps of the six sub-locations used to randomly identify existing informal settlements in Kisumu [19]. In the second stage, we selected existing water points within informal settlements, and randomly selected starting points located near the water points. This strategy was driven by the use of watering points as navigation tools by the local communities. We subsequently carried out systematic sampling, with every nth household interviewed. Approximately $98 \%$ of the targeted households could be interviewed.

\section{Data collection}

The survey was administered as a structured questionnaire using Open Data Kit (ODK) software on handheld tablets to answer questions on household composition; household assets; household expenditure and consumption; and health-seeking behaviour. Research assistants who were fluent in English, Kiswahili and the local dialect, Luo, and who had knowledge of the local geographical and sociocultural context were hired. Training was provided to familiarise research assistants with the questionnaire and data collection using handheld tablets.

Household heads were targeted as the primary respondents for this study. In cases where the household head was not available, their spouse was interviewed.

In order to identify the informally employed in our study area, we used a deductive approach of identifying households where the household head did not make mandatory monthly payments into the National Social Security Fund (NSSF). This approach was taken, as there is no clearly defined approach for identifying the informal sector in Kenya. However, the formal sector is defined distinctly within Kenya's legal framework, with sector members legally obligated to make monthly pension payments to the NSSF [32].

Insured households were defined as those where members were voluntarily enrolled into the NHIF in the year preceding the study.

\section{Statistical analysis}

The data were analysed using STATA version 14.1 for Windows (STATA Corporation, College Station, Texas). The main outcome variable was voluntary enrolment into the NHIF in the previous year. The explanatory variables were divided into five components: household composition and attributes; household head factors; perceived household health status; and proxies for exposure to financial risk pooling.

In order to measure wealth, we used the asset index as described within the Kenya Demographic and Health Survey (DHS) to calculate households' asset-based wealth [21]. We collected data on consumer items, dwelling 
characteristics such as housing materials, water source, sleeping arrangements, and other characteristics linked to wealth status. We subsequently computed the asset index. Households were then classified into one of five socioeconomic groups based on quintiles (Q): Q1 or the poorest 20\%; Q2; Q3; Q4; and Q5 or the wealthiest $20 \%$ in the sample. These groups were subsequently clustered into three groups: Q1 and Q2; Q3 and Q4; and Q5 respectively, to account for the minimal differences amongst the proximal quintiles. Literacy within the study context was defined as those above the age of 15 years who could read and write [37]. The mean perceived health status of each household was calculated as the average self-reported health status value for all household members. The final value of the mean perceived health status was assigned a value of between 1 and 4, with 1 being "very good" health status; 2 being "good" health status; 3 being "poor" health status; and 4 being "very poor" health status.

We used multilevel mixed-effects logistic regression models to estimate the association between health insurance enrolment and the explanatory variables. We took the clustering of households at the village level into account using random effects for village. In light of the low numbers of insured households within our study population, it was not possible to include multiple covariates simultaneously in the model. Therefore, univariate models were run to estimate the association of each variable and health insurance enrolment for the ROSCA and non-ROSCA households respectively. We ran the regression models for (i) ROSCA and non-ROSCA separately to easily gain estimates of the univariate odds ratios and 95\% confidence intervals; and (ii) on the full dataset with ROSCA and non-ROSCA households in order to use interaction terms to directly test whether the associations between each covariate and NHIF enrolment were affected by ROSCA membership. Each model included the covariate, ROSCA membership, and the interaction term as explanatory variables.

\section{Results}

\section{Study population characteristics}

A total of 444 households were enumerated in the survey, with ROSCA member households accounting for $63 \%$ of the study population. Approximately $29 \%$ of ROSCA households and 23\% of non-ROSCA households were voluntarily enrolled into the NHIF. While ROSCA members are actively targeted by the NHIF for enrolment, our study did not find a statistically significant association between ROSCA membership and health insurance enrolment (OR: 1.33 [0.85-2.09]). Table 1 reports the differences in each test variable according to insurance status and household ROSCA membership status.
Most household heads in our study population reported themselves as economically active, with $94 \%$ of respondents carrying out casual income-generating activities in lieu of formal employment. The most common economic activities amongst our study population were small-scale business ventures, with $56 \%$ of the population engaging in activities such as carpentry, masonry, and hairdressing. This notwithstanding, our findings revealed that $26 \%$ of our study population lived below the poverty line, which is defined as a household income of less than $\$ 1.90$ a day [41].

The household characteristics and health status for the sample population were broadly similar regardless of ROSCA membership status. Overall, the median household size was 4 , with $77 \%$ of all households having children below the age of 15 years. The number of households with elderly members was low across the study population, with only $8 \%$ of households having members above the age of 65 years. The study population also showed similarities in the gender and marital status of household heads, irrespective of ROSCA membership status. Further, the study found similarities in the mean household health status, with $5 \%$ of households reporting the presence of chronic disease.

The study found important distinctions in the economic characteristics of ROSCA and non-ROSCA households. ROSCA members were more likely to have more than one earner in the household and higher monthly incomes compared to non-members.

\section{Factors associated with voluntary health insurance enrolment amongst ROSCA and non-ROSCA member households}

Household-level regression results are presented in Table 2 for ROSCA and non-ROSCA member households.

Our study found that education and asset-based SES were associated with NHIF demand, regardless of ROSCA membership status. Household heads in the study population were more likely to enrol into the national health insurance scheme if they were educated to at least secondary school level $(\mathrm{OR}=1.80$ (CI:1.05-3.11) for ROSCA members, and OR $=3.23$ (CI:1.47-7.08) for non-ROSCA members (interaction test $=0.84$ ). Our findings also suggest that SES was associated with health insurance demand, although there was no evidence that the strength of the association was influenced by ROSCA membership status ( $p$-value $=0.47$ ).

Our analysis showed that the relationship between NHIF enrolment and some socio-demographic and economic variables could be influenced by a household's ROSCA status. The study found that household heads that were self-employed or had no fixed employment were significantly less likely to enrol into the NHIF if they did not belong to a ROSCA ( $p$-value $=0.03$ ). 
Table 1 Descriptive statistics by gender and insurance status

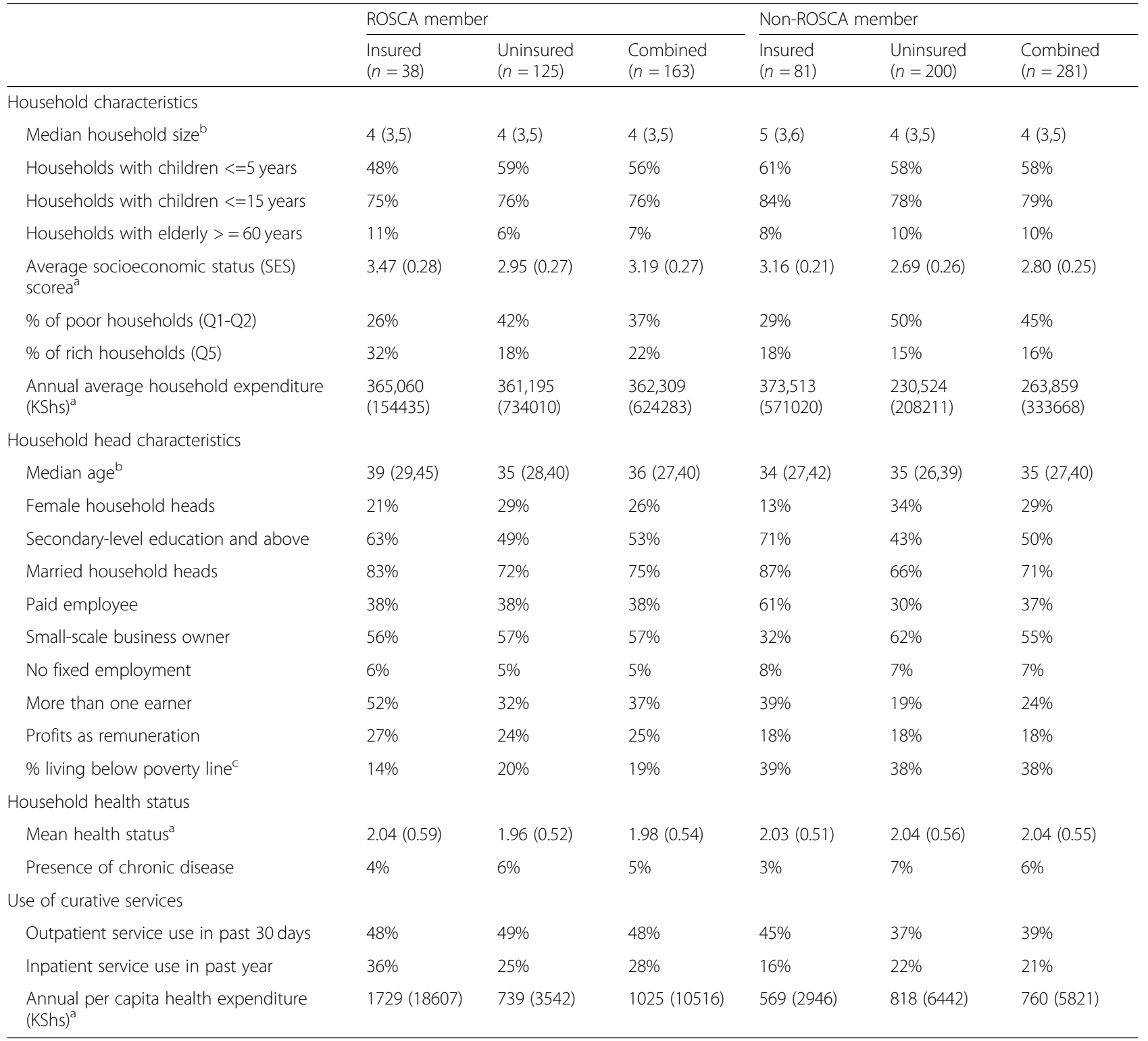

${ }^{\mathrm{a}}$ Mean ( \pm Standard Deviation)

${ }^{\mathrm{b}}$ Median (Inter-Quartile Range)

'Poverty line defined as households living on less than $\$ 1.90$ a day

$1 \mathrm{USD}=102.45 \mathrm{KSh}$ as of January 2018

Our findings also raise the possibility of a stronger relationship between gender and national health insurance demand if one does not belong to a ROSCA than if one does $(p$-value $=0.09)$. According to our analysis, non-ROSCA female household heads were less likely to enrol into the NHIF compared with their male counterparts $(\mathrm{OR}=0.29$ (CI:0.11-0.79). The odds ratio among the ROSCA member group was 0.65 (CI:0.35-1.23). Given the low treatment numbers amongst the insured, the borderline effect of ROSCA membership on the relationship between gender and health insurance demand infers that it may play an influencing role on the association between the explanatory variable and NHIF enrolment.

In addition to the above associations, our findings suggest that NHIF demand may increase if the household head was married or received a fixed salary. There was, however, no evidence that these associations were influenced by ROSCA membership.

\section{Discussion}

This study investigated the influence of informal financial coping mechanisms on the demand for formal, more 
Table 2 Univariate logistic estimates for probability of purchasing NHIF health insurance at household level

\begin{tabular}{|c|c|c|c|c|c|}
\hline \multirow[b]{2}{*}{ Variable description } & \multicolumn{2}{|c|}{ ROSCA members $(n=163)$} & \multicolumn{2}{|c|}{ Non-ROSCA members $(n=281)$} & \multirow{2}{*}{$\begin{array}{l}\text { Interaction* }(n=444) \\
p \text {-value }\end{array}$} \\
\hline & Odds ratio & $\mathrm{Cl}$ & Odds ratio & $\mathrm{Cl}$ & \\
\hline \multicolumn{6}{|l|}{ Household characteristics } \\
\hline Presence of children $<15$ years & 0.92 & $0.49-1.72$ & 1.54 & $0.59-4.05$ & 0.50 \\
\hline Presence of elderly $>60$ years & 1.93 & $0.76-4.90$ & 0.74 & $0.20-2.74$ & 0.15 \\
\hline \multicolumn{6}{|c|}{ Socioeconomic status (Reference group: First and second quintiles) } \\
\hline Middle wealth & 1.71 & $0.91-3.23$ & 2.56 & $1.12-5.88$ & 0.47 \\
\hline Wealthiest quintile & 2.81 & $1.38-5.73$ & 2.08 & $0.71-6.10$ & \\
\hline \multicolumn{6}{|l|}{ Household head characteristics } \\
\hline \multicolumn{6}{|c|}{ Sex of household head (Reference group: Male) } \\
\hline Female & 0.65 & $0.35-1.23$ & 0.29 & $0.11-0.79$ & 0.09 \\
\hline \multicolumn{6}{|l|}{ Age (Reference group: $\leq 24$ years) } \\
\hline $25-29$ years & 0.71 & $0.27-1.90$ & 1.29 & $0.35-4.72$ & 0.16 \\
\hline $30-45$ years & 0.92 & $0.38-2.22$ & 2.16 & $0.65-7.17$ & \\
\hline $46-59$ years & 1.92 & $0.68-5.42$ & 1.79 & $0.41-7.86$ & \\
\hline $60+$ years & 1.92 & $0.59-6.24$ & 0.42 & $0.04-4.18$ & \\
\hline \multicolumn{6}{|c|}{ Education (Reference group: Primary level or less) } \\
\hline Secondary education or higher & 1.80 & $1.05-3.11$ & 3.23 & $1.47-7.08$ & 0.84 \\
\hline \multicolumn{6}{|c|}{ Employment type (Reference group: Paid employees) } \\
\hline Self-employed & 0.95 & $0.55-1.66$ & 0.25 & $0.11-0.57$ & 0.03 \\
\hline No fixed employment & 1.15 & $0.35-3.75$ & 0.55 & $0.14-2.25$ & \\
\hline \multicolumn{6}{|c|}{ Remuneration (Reference group: Fixed salary) } \\
\hline Daily/hourly pay & 0.70 & $0.29-1.71$ & 0.20 & $0.07-0.53$ & 0.19 \\
\hline Task-based payment & 0.52 & $0.23-1.14$ & 0.15 & $0.05-0.44$ & \\
\hline Business profits & 0.76 & $0.33-1.76$ & 0.32 & $0.11-0.95$ & \\
\hline \multicolumn{6}{|c|}{ Marital status (Reference group: Unmarried) } \\
\hline Married & 1.87 & $0.96-3.64$ & 3.46 & $1.26-9.51$ & 0.57 \\
\hline Presence of chronic illness in household & 0.65 & $0.17-2.44$ & 0.35 & $0.43-2.84$ & 0.46 \\
\hline
\end{tabular}

*The $p$-values assess whether the association between each variable and NHIF membership is significantly different for the ROSCA and non-ROSCA households The odds in the reference group are multiplied by the odds ratio for each category

secure forms of financial risk protection in health. Before probing the associations between ROSCA membership and health insurance enrolment, it is first necessary to examine the overarching determinants of NHIF demand within the general population sample. According to our findings, the NHIF has been successful in providing inclusive health insurance coverage regardless of household composition or health status. This may be attributed to the NHIF's benefit structure, which enables a household to enrol all its identified dependants under a fixed premium irrespective of their individual circumstances. While successful in expanding coverage amongst the above-mentioned groups in our study area, we found that the NHIF still faces challenges in increasing health insurance demand amongst key vulnerable population groups, including those with low levels of education and limited asset-based wealth. These findings reflect similar national health financing studies across sub-Saharan Africa that have identified a positive correlation between health insurance demand and a household head's educational or asset-based socioeconomic status [10, 17, 25-27].

Viewed through the prism of ROSCA membership, our results inferred that sociocultural disenfranchisement due to female household headship reduced NHIF demand amongst those not involved in local ROSCAs. However, further analysis revealed that these sociocultural constraints on NHIF enrolment were limited amongst ROSCA members. With this in mind, it is necessary to examine how ROSCA membership changes the terms under which households engage with national power structures.

According to Mladovsky and Mossialos' social capital framework, bridging capital is vital in building norms and rules to facilitate productive behaviour in individuals [30]. Amongst these norms is the sharing of information 
and resources amongst socially heterogeneous groups, in order to create a fair market. In the context of ROSCAs, regular social and economic interaction minimizes the information and power asymmetry witnessed in the general population. ROSCAs thus challenge the power structures that are inherent within our study area by developing a common identity under which heterogeneous groups interact. This implies that ROSCAs may foster social cohesion amongst its members, ostensibly by arming different sociocultural groups with the information and financial resources to better understand and afford NHIF membership.

Based on our findings, however, it is, notable from our findings that ROSCA membership does not exclusively negate the influence of sociocultural biases on national health insurance demand. Cognisant of this, we postulate that the social alliances within ROSCAs are ultimately subservient to the economic power held by individuals. It is generally accepted that many ROSCAs exclude those unable to pay their dues during each payment cycle [13]. This means that the wealthy either self-select into the ROSCAs, or ultimately exclude their poorer counterparts due to non-payment of fees [2]. This leads to the pervasive exclusion of the economically marginalised, thus disempowering actors with weak economic agency. The role of potential ostracism in limiting the bridging social capital in ROSCAs is observed by the fact that the wealthier business owners in our study setting, either due to high household head income or multiple earners, were over-represented in ROSCA households. It is for this reason that we found that small-scale business owners were more likely to be enrolled into the NHIF if they had ROSCA membership.

It is important to view the findings of this manuscript within the context of the NHIF's broader Universal Health Coverage (UHC) strategy in Kenya. Since 2015, the Kenyan Government has provided fully subsidised NHIF coverage to indigents across the country through the Health Insurance Subsidy Programme for the Poor (HISP). This scheme has set the ambitious goal of expanding health insurance coverage to 9 million indigents across the country by 2020 [28]. Additionally, in 2016, the Kenyan Government began offering free maternity services (FMS) to all Kenyan women through the NHIF (Kenya National [23]). With these programmes in mind, the NHIF's ROSCA targeting strategy would ostensibly be targeted towards a narrow group of informal sector workers who have some degree of economic agency. With this nuanced lens, the NHIF's strategy of targeting the informal sector through ROSCAs may be feasible, given their alternative means of targeting those at the bottom of the pyramid through premium subsidisation. However, the success of these strategies will be highly dependent upon the successful planning and execution of these collaborative strategies as collective, as well as effectively identifying households at the bottom of the pyramid.

Given the indefinite nature of social capital, care must be taken in viewing the associations reported in this study as causal. We must also acknowledge that the structures of ROSCAs and their relationships with stocks of social capital will vary considerably. We note that ROSCA membership may be influenced by several non-observable factors, such as time-availability and self-selection, which directly impact one's ability to participate in ROSCAs. We further acknowledge that the use of univariate logistic regression in our study limits our ability to control for some key confounders within our analysis. We therefore reiterate that the relationship between ROSCA membership and its associated social capital, NHIF enrolment and the explanatory variables is associative rather than causative within the context of our study. Further, the urban setting of this study limits its external validity in rural areas. Nevertheless, this article provides an insight into the transmutability of social capital from the local level to national level. It also provides an insight into how an in-depth understanding of the social and economic characteristics of target populations can feed into in the design of national-level schemes. Our study has several design limitations that may affect the external validity of our study: the study took place in the transitory period during which changes to NHIF rates and benefits for the informal sector were being negotiated. Due to this context, the study's applicability may be affected by the new NHIF voluntary health insurance regime.

\section{Conclusion}

This study examined the influence of ROSCA membership and social capital on voluntary health insurance enrolment. We posit that socially disadvantaged groups may accrue strong bridging social capital by participating in ROSCAs in resource-poor areas. However, we suggest that the full benefits of social capital in increasing health insurance demand can only be accrued by taking into account the underlying economic situation of the target population. We note that the educational and financial situation of a household serves as a strong indicator of its capacity to make investment decisions, including signing up to a voluntary health insurance scheme. It is therefore important to anchor outreach to ROSCAs within a broader, multi-pronged approach that targets households within their social, economic and political realities. These findings are particularly relevant to countries that may seek to increase voluntary health insurance coverage through local associations: it is important to understand the demographic challenges of these groups and utilise several strategies and targeting mechanisms to ensure equitable access to health insurance for all citizens. 


\section{Abbreviations}

DHS: Demographic and Health Survey; FMS: Free Maternity Services; HISP: Health Insurance Subsidy Programme for the Poor; NHIF: National Hospital Insurance Fund; NSSF: National Social Security Fund; ODK: Open Data Kit; ROSCAs: Rotating Savings and Credit Associations; SES: Socioeconomic Status; UHC: Universal Health Coverage

\section{Acknowledgements}

The authors would like to thank the Kisumu County team for their cooperation on this project. The author would also like to thank the Assistant Chiefs of Manyatta A, Manyatta B, Nyalenda, and Obunga for providing consent for data collection in their areas. The authors acknowledge Pamoja Trust for availing the Kisumu informal settlement enumeration maps used for sampling. Finally, the authors also thank Dr. Amanda Ross (Swiss TPH) for statistical support provided.

\section{Funding}

Data collection was financed by the Swiss Tropical and Public Health Institute (Swiss TPH). TO is a recipient of the Swiss Government Excellence Scholarship (ESKAS), provided by the Swiss Federal Commission for Scholarships for Foreign Students (FCS).

\section{Availability of data and materials}

Please contact author for data requests.

\section{Authors' contributions}

TO designed and collected the data for the study. TO completed data analysis and drafted the manuscript for publication. KW helped draft and review the manuscript for intellectual content. Both authors read and approved the final version.

\section{Ethics approval and consent to participate}

Ethical approval for this study was obtained through the Institutional Review Board (IRB) of Strathmore University, Kenya (Ethics Reference No. SU-IRB 0057/16; Date of approval: 15th June 2016). Written consent was acquired from all respondents.

\section{Consent for publication}

Not applicable.

\section{Competing interests}

The authors declare that they have no competing interests.

\section{Publisher's Note}

Springer Nature remains neutral with regard to jurisdictional claims in published maps and institutional affiliations.

\section{Author details}

${ }^{1}$ Swiss Tropical and Public Health Institute, Basel, Switzerland. ${ }^{2}$ University of Basel, Basel, Switzerland. ${ }^{3}$ Department of Epidemiology and Public Health, Health Systems Support Unit, Swiss Tropical and Public Health Institute, P.O. Box 4002, Basel, Switzerland.

Received: 15 March 2018 Accepted: 9 November 2018

Published online: 20 November 2018

\section{References}

1. Adebayo EF, Uthman OA, Wiysonge CS, Stern EA, Lamont KT, Ataguba JE. A systematic review of factors that affect uptake of community-based health insurance in low-income and middle-income countries. BMC Health Serv Res. 2015;15(543). https://doi.org/10.1186/s12913-015-1179-3.

2. Anderson S, Baland J-M, Moene KO. Enforcement in informal saving groups. J Dev Econ. 2009;90:14-23. https://doi.org/10.1016/j.jdeveco.2008.09.003.

3. Biggart, N., 2001. Banking on each other: the situational logic of rotating savings and credit associations.

4. Bourdieu P. The forms of capital, in: handbook of theory and research for the sociology of education. Westport, CT: Greenwood; 1986. p. 241-58.

5. Buigut S, Ettarh R, Amendah DD. Catastrophic health expenditure and its determinants in Kenya slum communities. Int J Equity Health. 2015;14:46.

6. Busse R, Blümel M, Knieps F, Bärnighausen T. Statutory health insurance in Germany: a health system shaped by 135 years of solidarity, self- governance, and competition. Lancet. 2017;390:882-97. https://doi.org/10. 1016/S0140-6736(17)31280-1.

7. Central Bank of Kenya, Kenya National Bureau of Statistics, FSD Kenya, 2016. The 2016 FinAccess Household Survey on financial inclusion. FSD Kenya, Nairobi, Kenya.

8. Coleman, J.S., 1990. The foundations of social theory.

9. Demirguc-Kunt, A., Klapper, L., Singer, D., Van Oudheusden, P., 2015. The Global Findex Database 2014: Measuring Financial Inclusion around the World (Policy Research Working Paper No. 7255). World Bank Group, Washington, D.C.

10. Dixon J, Luginaah I, Mkandawire P. The National Health Insurance Scheme in Ghana's upper west region: a gendered perspective of insurance acquisition in a resource-poor setting. Soc Sci Med. 2014;1982(122):103-12. https://doi.org/10.1016/j.socscimed.2014.10.028.

11. Donfouet HPP, Makaudze E, Mahieu P-A, Malin E. The determinants of the willingness-to-pay for community-based prepayment scheme in rural Cameroon. Int J Health Care Finance Econ. 2011;11:209. https://doi.org/10. 1007/s10754-011-9097-3.

12. Dupas $P$, Robinson J. Savings constraints and microenterprise development evidence from a field experiment in Kenya. Am Econ J Appl Econ. 2013;5: $163-92$

13. Edoardo, T., 2013. Exploring the black-box of economic informality: social networks and institutional change among micro and small Enterprises in Nairobi, Kenya, in: securing livelihoods. Oxford University Press, Oxford https://doi.org/10.1093/acprof:oso/9780199687015.003.0010.

14. Fadlallah R, El-Jardali F, Hemadi N, Morsi RZ, Abou Samra CA, Ahmad A, Arif K, Hishi L, Honein-AbouHaidar G, AkI EA. Barriers and facilitators to implementation, uptake and sustainability of community-based health insurance schemes in low- and middle-income countries: a systematic review. Int J Equity Health. 2018;17(13). https://doi.org/10.1186/s12939-018-0721-4

15. Fenenga CJ, Nketiah-Amponsah E, Ogink A, Arhinful DK, Poortinga W, Hutter I. Social capital and active membership in the Ghana National Health Insurance Scheme - a mixed method study. Int J Equity Health. 2015; 14(118). https://doi.org/10.1186/s12939-015-0239-y.

16. Hayes RJ, Bennett S. Simple sample size calculation for cluster-randomized trials. Int J Epidemiol. 1999:28:319-26. https://doi.org/10.1093/ije/28.2.319.

17. Jehu-Appiah C, Aryeetey G, Agyepong I, Spaan E, Baltussen R. Household perceptions and their implications for enrolment in the National Health Insurance Scheme in Ghana. Health Policy Plan. 2012;27:222-33. https://doi. org/10.1093/heapol/czr032.

18. Jehu-Appiah C, Aryeetey G, Spaan E, de Hoop T, Agyepong I, Baltussen R. Equity aspects of the National Health Insurance Scheme in Ghana: who is enrolling, who is not and why? Soc Sci Med. 2011;72:157-65. https://doi. org/10.1016/j.socscimed.2010.10.025.

19. Karanja I. An enumeration and mapping of informal settlements in Kisumu, Kenya, implemented by their inhabitants. Environ Urban. 2010;22:217-39. https://doi.org/10.1177/0956247809362642.

20. Kenya National Bureau of Statistics, 2017. Economic Survey 2017. Government of Kenya.

21. Kenya National Bureau of Statistics, 2015. Kenya Wealth Index

22. Kenya National Bureau of Statistics, 2010. The 2009 Kenya Population and Housing Census. Kenya National Bureau of Statistics, Nairobi, Kenya.

23. Kenya National Treasury, 2017. Budget statement for the fiscal year 2017/ 2018. Government of Kenya.

24. Kimani JK, Ettarh R, Kyobutungi C, Mberu B, Muindi K. Determinants for participation in a public health insurance program among residents of urban slums in Nairobi, Kenya: results from a cross-sectional survey. BMC Health Serv Res. 2012;12(66). https://doi.org/10.1186/1472-6963-12-66.

25. Kimani JK, Ettarh R, Warren C, Bellows B. Determinants of health insurance ownership among women in Kenya: evidence from the 2008-09 Kenya demographic and health survey. Int J Equity Health. 2014;13:27. https://doi. org/10.1186/1475-9276-13-27.

26. Macha J, Kuwawenaruwa A, Makawia S, Mtei G, Borghi J. Determinants of community health fund membership in Tanzania: a mixed methods analysis. BMC Health Serv Res. 2014;14(538). https://doi.org/10.1186/s12913-014-0538-9.

27. Mebratie AD, Sparrow R, Yilma Z, Alemu G, Bedi AS. Enrollment in Ethiopia's community-based health insurance scheme. World Dev. 2015;74:58-76. https://doi.org/10.1016/j.worlddev.2015.04.011.

28. Ministry of Health, 2016. Health Sector Working Group Report: Medium Term Expenditure Framework for the Period 2017-18 to 2019-20. Government of Kenya, Nairobi. 
29. Ministry of Health, 2013. Kenya Household Health Expenditure and Utilisation Survey (KHHEUS) 2013 Questionnaire.

30. Mladovsky P, Mossialos E. A conceptual framework for community-based health insurance in low-income countries: social capital and economic development. World Dev. 2008;36:590-607.

31. Mladovsky P, Soors W, Ndiaye P, Ndiaye A, Criel B. Can social capital help explain enrolment (or lack thereof) in community-based health insurance? Results of an exploratory mixed methods study from Senegal. Soc Sci Med. 2014;101:18-27. https://doi.org/10.1016/j.socscimed.2013.11.016.

32. National Council for Law Reporting, 1989. The National Social Security Fund act, in: Laws of Kenya. The Republic of Kenya.

33. National Hospital Insurance Fund, 2017a. Expanding Social Health Insurance Coverage among the Informal Sector: Strategy 2016-2018. Government of Kenya, Nairobi, Kenya.

34. Putnam RD. What makes democracy work? Natl Civ Rev. 1993;82:101-7. https://doi.org/10.1002/ncr.4100820204.

35. Szreter S, Woolcock M. Health by association? Social capital, social theory, and the political economy of public health. Int J Epidemiol. 2004;33:650-67. https://doi.org/10.1093/ije/dyh013.

36. Tatara, K., Okamoto, E., 2009. Japan: Health system review, in: Health Systems in Transition. pp. 1-164.

37. UNESCO, 2006. Understandings of literacy, in: education for all global monitoring report 2006. UNESCO Publishing, Paris.

38. United Nations General Assembly, 2012. Global Health and foreign policy. Agenda Item 123.

39. World Bank, JICA, The Global Fund, African Development Bank, WHO, 2016 Universal health coverage in Africa: A framework for action, in: Joint 2016 TICAD Conference Working Paper.

40. World Health Organization, 2010. The world health report: health systems financing: the path to universal coverage. World Health Organization, Geneva.

41. World Health Organization, International Bank for Reconstruction and Development/World Bank, 2017. Tracking Universal Health Coverage: 2017 Global Monitoring Report.

42. Zollman J. Kenya financial diaries: Shilingi kwa shilingi, the financial lives of the poor. Nairobi, Kenya: FSD Kenya; 2014

Ready to submit your research? Choose BMC and benefit from:

- fast, convenient online submission

- thorough peer review by experienced researchers in your field

- rapid publication on acceptance

- support for research data, including large and complex data types

- gold Open Access which fosters wider collaboration and increased citations

- maximum visibility for your research: over $100 \mathrm{M}$ website views per year

At $\mathrm{BMC}$, research is always in progress.

Learn more biomedcentral.com/submissions 